\title{
Characterization of Infertility using Ultrasonography
}

\author{
Manal Z. A. Zeinalabdeen*, Mohamed E. M. Gar-Elnabi
}

College of Medical Radiological Science, Sudan University of Science and Technology, Khartoum, Sudan

DOI: $10.36347 /$ sjams.2020.v08i10.021

| Received: 30.09.2020 | Accepted: 14.10.2020 | Published: 19.10.2020

*Corresponding author: Manal Zeinalabdeen

Abstract

The aim of this study to characterize the fertility in women using ultrasound through the uterine blood flow indices and uterus dimension. The sample consisted of 100 women; 50 of them were infertile and the other 50 were fertile women taken as control group. The result of this study showed that there is a significant difference between the fertile and infertile women in case of the uterus length and size, the uterus width and blood flow indices showed inconclusive result. The relationship of blood flow indices to uterine dimension showed a significant linear association between the uterus length and PI and PSV for the infertile women. While it shows similar relationship with the uterus length and area, and PI and PSV (multiple regression). These relationships were reverse in case of the fertile and infertile. For the infertile group there is an inverse linear relationship between the PI and uterus length and direct linear relationship between the PSV and uterus length. In case of fertile group there is a direct linear relationship between the PI and the uterus length (and uterus size) and inverse linear relationship between the PSV and uterus length and uterus size.

Keywords: Fertility, ultrasound, uterus, PSV.

Copyright $\odot 2020$ The Author(s): This is an open-access article distributed under the terms of the Creative Commons Attribution 4.0 International License (CC BY-NC 4.0) which permits unrestricted use, distribution, and reproduction in any medium for non-commercial use provided the original author and source are credited.

\section{INTRODUCTION}

Ultrasonography is integral to assessing such women, and the transvaginal approach is now standard. While the majority of transvaginal ultrasound scans will provide a diagnosis, a proportion will remain nondiagnostic. In these cases, if an intrauterine gestation sac has been identified, this is classified as a pregnancy of uncertain viability. If a pregnancy has not been visualized either inside or outside the uterus, it is described as a pregnancy of unknown location. Neither of these terms is a diagnosis; they simply describe the diagnostic position at a moment in time.

As pelvic ultrasound (US) was introduced in the early 1980s, this new and noninvasive technique allowed morphological assessment of the ovaries on a wide scale. Sonographic appearance of polycystic ovaries became an important criterion for PCOS diagnosis [1-3]. In fact, many investigators now use US as the sole criterion for diagnosis of this syndrome [2-4]. Sonographically diagnosed polycystic ovaries can be enlarged [5,6], contain an increased number of follicles $(5,11 /$, or exhibit an increased amount or density of stroma $[1,8]$. These characteristics are sometimes used as a single parameter or are combined $[1,2,8]$. At present, transvaginal sonography with enhanced resolution is most commonly used for US evaluation of ovaries.
However, criteria determined by transabdominal US still are used frequently $[2,7,9]$.

The evaluation of infertility requires reliable, diagnostically accurate, minimally invasive, efficient, and cost-effective approaches. For the last several decades, the evaluation of female infertility has involved numerous and complex diagnostic modalities, some of which are invasive or use ionizing radiation and or contrast, such as hysterosalpingography, hysteroscopy, and magnetic resonance imaging (MRI). Meanwhile, ultrasound has matured into a modality that can provide most - and often all — of the same information necessary to diagnose or exclude anatomic abnormalities of the female reproductive tract [10]. In addition, ultrasound, as a real-time technique, provides the practitioner with the opportunity to examine the patient while she is being imaged. This combination of imaging with the patient interview and physical examination can yield information regarding focal pain or lack of movement of organs unobtainable by other imaging modalities $[11,12]$.

Doppler techniques provide images depicting the vascularity and perfusion of the organs, providing crucial additional information as part of the examination of the female pelvis [11]. Finally, after introduction of saline through an endometrial catheter, ultrasound can 
evaluate the endometrial cavity and the patency of the tubes [13].

\section{Evaluation of the uterus}

The uterus is typically examined transvaginally with a high-frequency transducer, after the patient has emptied her bladder. The uterus is first imaged longitudinally, along the sagittal plane with the cervix at one end of the image and the fundus. This approach then permits imaging of the endometrium, the junctional zone between the endometrium and the myometrium, and the echotexture and symmetry of the myometrium [14]. The transducer is then rotated to obtain a transverse view of the uterus so that it can be evaluated from top to bottom. The uterus can be measured in three dimensions from these two views. The length measurement typically includes the cervix unless the volume of the uterus is calculated [14]. Several studies support the advantages of 3D ultrasound over 2D ultrasound [15, 16], hysteroscopy [17, 18], hysterosalpingography $[19,20]$, and MRI for the evaluation of uterine malformations [15]. The diagnostic accuracy of both 3D ultrasound and MRI is $90 \%$ to $95 \%$ for detecting the specific type of uterine anomaly [18, 21].

\section{Methodology}

This study will be achieved in different hospitals and clinics in Sudan, the population of this study are 100 patients. Transabdominal US was performed using a G40 scanner with a $3.5-$ to $5-\mathrm{MHz}$ convex and a 6-to $10-\mathrm{MHz}$ linear probe (Siemens Ultrasound Mountain View, CA) with the conventional full bladder technique and interpreted by an experienced radiologist.

The data collected using data collection sheet contain different variables: the patent information such as age, weight and high while the measurement information echogenicity, texture, size, blood flow indicates and level of hormones.

\section{Technique and protocol}

The uterus represents the essential landmark of pelvic anatomy. The main aspects that can be evaluated through ultrasonography are:

The position. Usually the uterus has a midcentral situation within the pelvis. A lateral position is seldom encountered and it is realized around the axis of the uterine isthmus. The anteverted-anteflexed uterus, with the uterine body found in the vesico-uterine space, is the most frequent situation compared with the retrovertedretroflexed uterus, when the uterine body is situated in the Douglas pouch.

The size. The following measurements are obtained during the ultrasound evaluation of the uterus: the length - the distance from the fundus to the internal orifice of the uterus on a sagittal view; the width - the maximum anterior-posterior distance measured in the mid portion of the uterine body also on a sagittal view; the thickness - the maximum distance measured at the level of the uterine fundus on a transverse view.

The shape. On a sagittal plane the uterus has a pyriform shape: the superior two thirds correspond to the uterine body and the inferior third to the cervix. The uterine isthmus is identified where the uterine body and cervix meet. On the transverse view the uterine body has an oval shape, with a transverse long axis, while the isthmus and the cervix have a round shape.

\section{RESULTS}

Table-1: The mean and standard deviation of the age, blood flow indices and uterus dimensions for fertile and infertile women

\begin{tabular}{|l|l|l|}
\hline Variables & $\begin{array}{l}\text { Mean } \pm \text { SD } \\
\text { infertile }\end{array}$ & $\begin{array}{l}\text { Mean } \pm \text { SD } \\
\text { Fertile }\end{array}$ \\
\hline Age & $30.2 \pm 7.1$ & $28.8 \pm 7.3$ \\
\hline PI & $0.79 \pm 0.4$ & $0.82 \pm 0.3$ \\
\hline RI & $2.564 \pm 1.5$ & $2.612 \pm 1.6$ \\
\hline PSV & $57.75 \pm 24.8$ & $50.83 \pm 24.2$ \\
\hline Uterus width & $5.44 \pm 0.2$ & $5.39 \pm 0.2$ \\
\hline Uterus length & $8.08 \pm 0.5$ & $8.66 \pm 0.3$ \\
\hline Uterus size & $44.08 \pm 4.6$ & $46.72 \pm 3.2$ \\
\hline
\end{tabular}

Table-2: Independent t-test between the fertile and infertile women for blood flow indices and uterus dimensions

\begin{tabular}{|l|l|l|}
\hline Variables & $\mathbf{p}$ & $\mathbf{t}$ \\
\hline PI & 0.08 & 0.43 \\
\hline RI & 0.73 & 0.17 \\
\hline PSV & 0.70 & 1.41 \\
\hline Uterus width & 0.29 & 1.28 \\
\hline Uterus length & 0.001 & 7.12 \\
\hline Uterus size & 0.026 & 3.33 \\
\hline
\end{tabular}

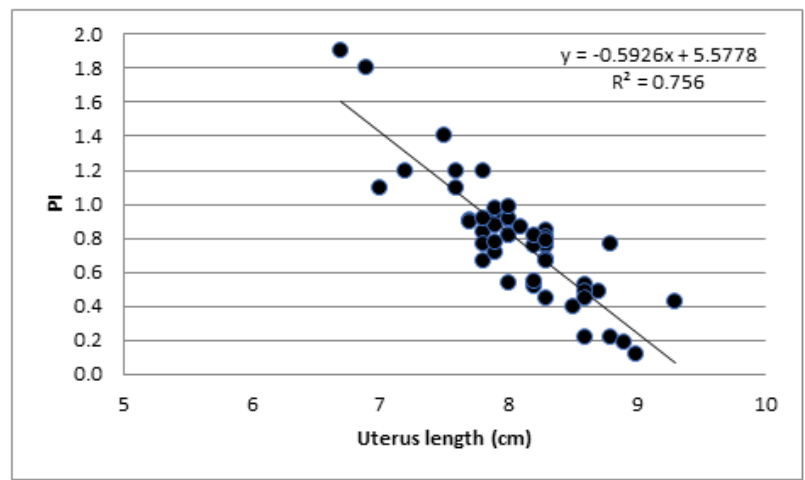

Fig-1: Scatter plot show an inverse linear relationship between the uterus length and PI of infertile women 


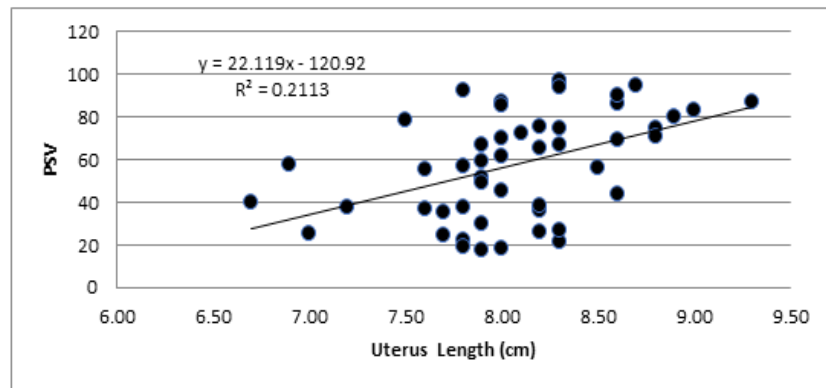

Fig-2: Scatter plot show direct linear relationship between the uterus length and PSV of infertile women

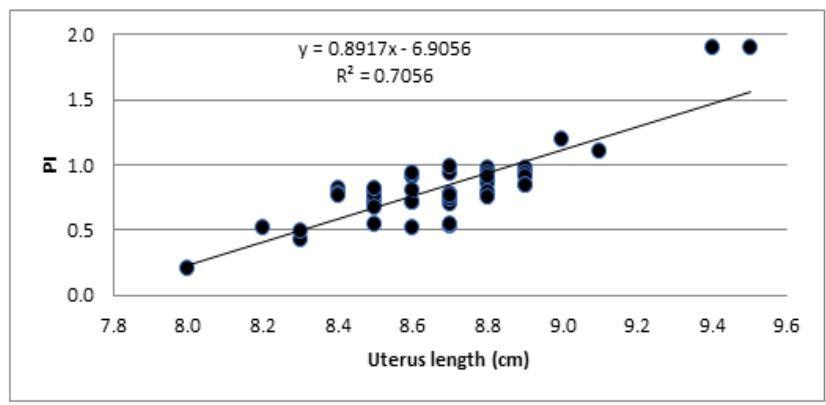

Fig-3: Scatter plot show direct linear relationship between the uterus length and PI of fertile women

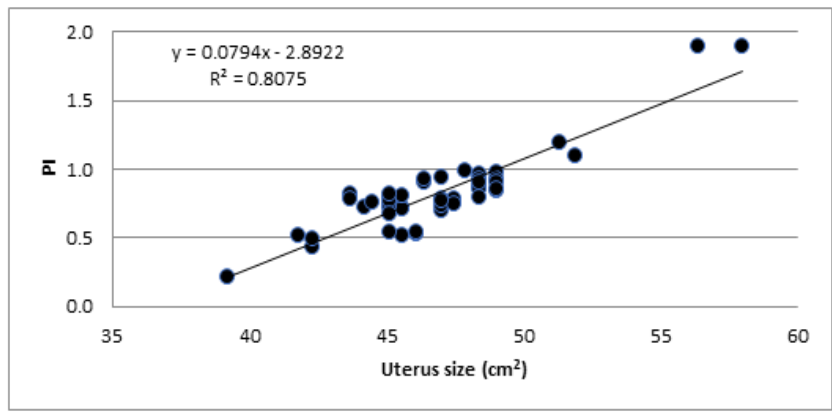

Fig-4: Scatter plot show direct linear relationship between the uterus size and PI of fertile women

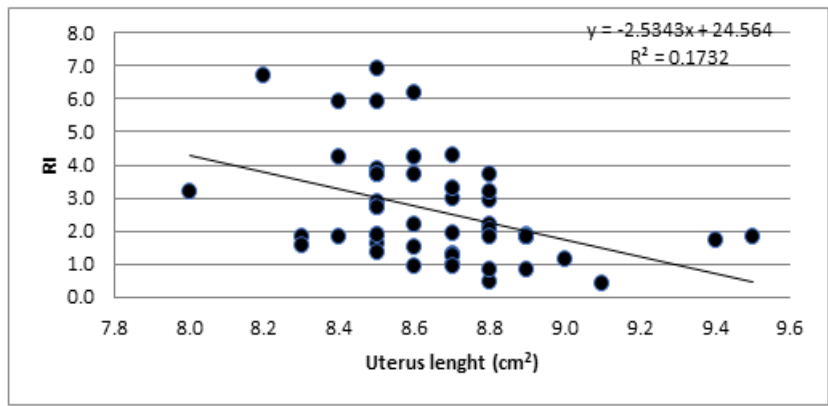

Fig-5: Scatter plot show inverse linear relationship between the uterus length and RI of fertile women

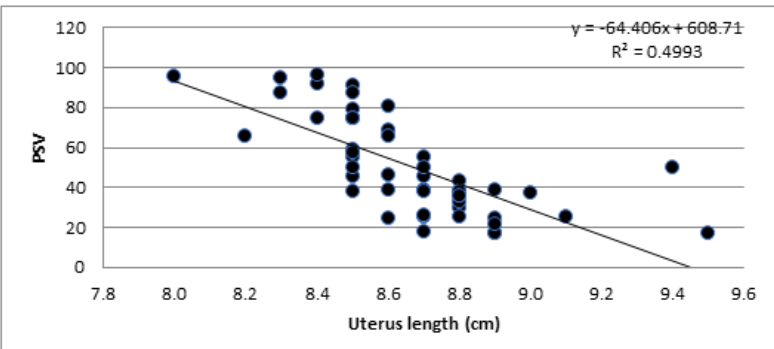

Fig-6: scatter plot show inverse linear relationship between the uterus length and PSV of fertile women

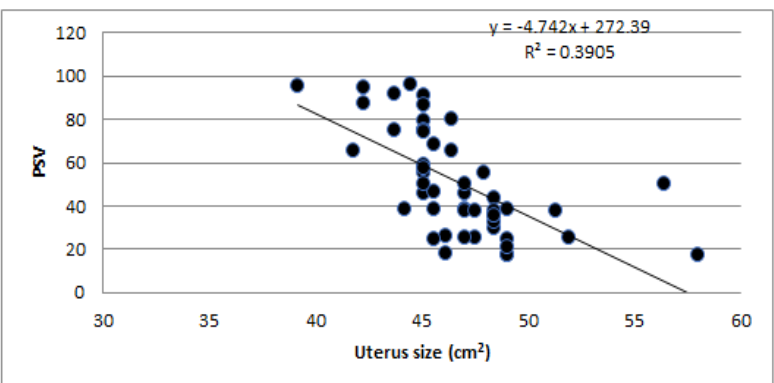

Fig-7: Scatter plot show inverse linear relationship between the uterus size and PSV of fertile women

\section{DISCUSSION}

The main objective of this study was to evaluate the characteristics of the infertility in the infertile women by studying the difference between the uterus size and blood flow in the fertile and infertile women. As shown in Table 1. Which gives the mean and standard deviation of blood flow indices and uterus dimension, there is some variation between the fertile and infertile women; these variation were significant at $\mathrm{p}=0.05$ using t-test for uterus length and size and inconclusive for the rest of the variables between the two groups (Table 2.). This result dictate that the length of the uterus which affected the size can be used to differentiate between the fertile and infertile women where it will be longer and larger in size in the fertile women than the infertile because it host a fetus which affects it is dimension regardless it is elasticity to go back to normal after delivery.

Although these differences might not be crucial in some situation; the relationship between the uterus dimension and blood flow indices can give a clear indication of the fertility. This study showed that there is a significant linear relationship between the PI and uterus length as well as PSV for infertile women. Where in case of PI and uterus length there is an inverse linear relationship in which the PI decreases by 0.59 units per each $1 \mathrm{~cm}$ of the uterus length starting from 5.6 as shown in Figure 1. PSV value show a significant direct linear association with the uterus length where the PSV increases by 22.1 units per each $1 \mathrm{~cm}$ of the uterus length starting -120 (Figure 2). These results also show that the blood flow indices (PI and PSV) can be estimated for the infertile women by using the uterus width and length as follows: PI $=(-0.59 \times$ uterus length $)$ 
+5.58 and PSV $=(22.12 \times$ uterus length $)-120.92$. RI does not show any significant linear relationship with the uterus dimension for this group.

For fertile women linear regression analysis showed that there is a significant linear association between the length and size of the uterus with the blood flow indices with no role to the uterus width. For PI there is a direct linear relationship with uterus length and size (multiple regressions) as shown individually in Figure 3. and 4. where the PI increases by 0.89 units per each $1 \mathrm{~cm}$ of the uterus length and by 0.08 units per each $1 \mathrm{~cm}^{2}$ of uterus size. This result showed that PI has a different relationship with the uterus length concerning fertility situation where it increases with the length for the fertile women and decreases with the length for the infertile one. The PI can be estimate for the fertile women using the following equation PI = $(0.89 \times$ uterus length $)-6.91$ or $\mathrm{PI}=(0.08 \times$ uterus size $)$ -2.89 .

The PSV in the fertile grouped showed a significant inverse linear relationship with the length and the size of the uterus (multiple regression). Where the PSV decreased by 64.4 units per each $\mathrm{cm}$ of the uterus length (Figure 6) and decreased by 4.7 units per each $\mathrm{cm}^{2}$ of uterus size. This relationship were opposite of the same relation in case of infertile women. Similarly the PSV can be estimated using the uterus length and size for the fertile women using the following equations: PSV $=(-64.41 \times$ uterus length $)+$ 608.71 or $\mathrm{PSV}=(-4.74 \times$ uterus size $)+272.39$.

The RI index also has an inverse linear relationship with the uterus length for the fertile group where the RI decreased by 2.5 units per each $1 \mathrm{~cm}$ of the uterus length and the RI can be estimated using the uterus length using the following equation $\mathrm{RI}=(-2.53 \times$ uterus length $)+24.56$. The RI index does not have significant linear relationship with uterus dimension in the infertile group as mentioned earlier; this is can be used as characteristic for both group.

\section{Conclusion}

The result of this study showed that there is a significant difference between the fertile and infertile women in case of the uterus length and size, the uterus width and blood flow indices showed inconclusive result. The relationship of blood flow indices to uterine dimension showed a significant linear association between the uterus length and PI and PSV for the infertile women. While it shows similar relationship with the uterus length and area, and PI and PSV (multiple regression). These relationships were reverse in case of the fertile and infertile.

For the infertile group there is an inverse linear relationship between the PI and uterus length and direct linear relationship between the PSV and uterus length. In case of fertile group there is a direct linear relationship between the PI and the uterus length (and uterus size) and inverse linear relationship between the PSV and uterus length (and uterus size).

\section{REFERENCES}

1. Adams J, Polson DW, Abdulwahid N, Morris DV, Franks S, Mason HD, Tucker M, Price J, Jacobs HS. Multifollicular ovaries: clinical and endocrine features and response to pulsatile gonadotropin releasing hormone. The Lancet. 1985 Dec 28;326(8469-8470):1375-9.

2. Adams J, Polson DW, Abdulwahid N, Morris DV, Franks S, Mason HD, Tucker M, Price J, Jacobs HS. Multifollicular ovaries: clinical and endocrine features and response to pulsatile gonadotropin releasing hormone. The Lancet. 1985 Dec 28;326(8469-8470):1375-9.

3. Fox R, Corrigan E, Thomas PA, Hull MG. The diagnosis of polycystic ovaries in women with oligo- amenorrhoea: predictive power of endocrine tests. Clinical endocrinology. 1991 Feb;34(2):12731.

4. Takahashi K, Eda Y, Okada S, Abu-Musa A, Yoshino K, Kitao M. Morphological assessment of polycystic ovary using transvaginal ultrasound. Human Reproduction. 1993 Jun 1;8(6):844-9.

5. Puzigaić Z, Prelevic GM, Stretenović Z, BalintPerić L. Ovarian enlargement as a possible marker of androgen activity in polycystic ovary syndrome. Gynecological Endocrinology. 1991 Jan $1 ; 5(3): 167-74$

6. Pache TD, de Jong FH, Hop WC, Fauser BC. Association between ovarian changes assessed by transvaginal sonography and clinical and endocrine signs of the polycystic ovary syndrome. Fertility and sterility. 1993 Mar 1;59(3):544-9.

7. Obhrai M, Lynch SS, Holder G, Jackson R, Tang L, Butt WR. Hormonal studies on women with polycystic ovaries diagnosed by ultrasound. Clinical endocrinology. 1990 Apr;32(4):467-74.

8. Dewailly D, Robert Y, Helin I, Ardaens Y, Thomas-Desrousseaux P, Lemaitre L, Fossati P. Ovarian Stromal Hypertrophy in Hyperandrogenic Women. Obstetrical \& Gynecological Survey. 1995 Apr 1;50(4):293-6.

9. Robinson S, Rodin DA, Deacon A, Wheeler MJ, Clayton RN. Which hormone tests for the diagnosis of polycystic ovary syndrome?. BJOG: An International Journal of Obstetrics \& Gynaecology. 1992 Mar;99(3):232-8.

10. Kelly SM, Sladkevicius P, Campbell S, Nargund G. Investigation of the infertile couple: a one-stop ultrasound-based approach. Hum Reprod. 2001;16:2481-4.

11. Sakhel K, Benson CB, Platt LD, Goldstein S, Benacerraf BR. Begin with the basics - the role of $3 \mathrm{D}$ ultrasound as a first line imaging technique in the cost-effective evaluation of gynecologic pelvic disease. J Ultrasound Med. 2013;32:381-8. 
12. Guerriero S, Ajossa S, Gerada M, D’Aquila M, Piras B, Melis GB. "Tenderness-guided" transvaginal ultrasonography: a new method for the detection of deep endometriosis in patients with chronic pelvic pain. Fertil Steril. 2007;88:1293-7.

13. Saunders RD, Shwayder JM, Nakajima ST. Current methods of tubal patencyassessment. Fertil Steril. 2011;95:2171-9.

14. American Institute of Ultrasound in Medicine. AIUM practice guideline forthe performance of pelvic ultrasound examinations. J Ultrasound Med. 2010;29:166-72.

15. Acien P. Incidence of Mullerian defects in fertile and infertile women. Hum Reprod. 1997;12:13726.

16. Bermejo C, Martínez Ten P, Cantarero R, Diaz D, Perez Pedregosa J, Barr on E. Three-dimensional ultrasound in the diagnosis of m€ ullerian duct anomalies and concordance with magnetic resonance imaging. Ultrasound Obstet Gynecol. 2010;35:593-601.

17. Caliskan E, Ozkan S, Cakiroglu Y, Sarisoy HT, Corakci A, Ozeren S. Diagnostic accuracy of realtime 3D sonography in the diagnosis of congenital $m €$ ullerian anomalies in high-risk patients with respect to the phase of the menstrual cycle. J Clin Ultrasound. 2010;38:123-7.

18. Faivre E, Fernandez H, Deffieux X, Gervaise A, Frydman R, Levaillant JM. Accuracy of threedimensional ultrasonography in differential diagnosis of septate and bicornuate uterus compared with office hysteroscopy and pelvic magnetic resonance imaging. J Minim Invasive Gynecol. 2012;19:101-6.

19. Ghi T, Casadio P, Kuleva M, Perrone AM, Gavelli L, Giunchi S. Accuracy of three-dimensional ultrasound in diagnosis and classification of congenital uterine anomalies. Fertil Steril. 2009;92:808-13.

20. Jurkovic D, Geipel A, Gruboeck K, Jauniaux E, Matucci M, Campbell S. Three-dimensional ultrasound for the assessment of uterine anatomy and detection of congenital anomalies: a comparison with hysterosalpingography and twodimensional sonography. Ultrasound Obstet Gynecol. 1995;5:233-7.

21. Deutch TD, Abuhamad AZ. The role of 3dimensional ultrasonography and magnetic resonance imaging in the diagnosis of $m €$ ullerian duct anomalies: a review of the literature. J Ultrasound Med. 2008;27:413-23. 